\title{
Primary Energy Balance driven Integrated Energy Design Process of Positive Energy Building
}

\author{
Meril Tamm ${ }^{*}{ }^{1,2}$, Joana Ortiz ${ }^{1}$, Jordi Pascual $^{1}$, Jarek Kurnitski ${ }^{2}$ and Martin Thalfeldt ${ }^{2}$, Jaume Salom ${ }^{1}$ \\ ${ }^{1}$ Thermal Energy and Building Performance Unit, Catalonia Institute for Energy Research, Jardins de les Dones de Negre 1, $2^{\mathrm{a}}$ pl. \\ 08930 Sant Adrià del Besòs, Barcelona, Catalonia, Spain. \\ ${ }^{2}$ Department of Civil Engineering and Architecture, Tallinn University of Technology, Ehitajate tee 5, \\ 19086 Tallinn, Estonia.
}

\begin{abstract}
The ISO 52000-1:2017 is the overarching Energy Performance of Buildings (EPB) standard, providing the general framework of the EPB assessment. It is applicable to the assessment of overall energy use of a building, by measurement or calculation, and the calculation of energy performance in terms of primary energy or other energy-related metrics. ISO 52000-1 provides general profound guidelines, but also gives the freedom to adapt the guidelines with national standards and regulations. This article focuses on design stage energy performance assessment in the framework of syn.ikia project, which aims to deliver a blueprint for an Integrated Design Process of sustainable plus energy buildings and neighbourhoods, leading the way to plus energy districts and cities. This project has four demonstration sites and the one being in focus of this article is located in Catalonia, Spain. Even though this project and Spanish Technical code both are based on ISO 52000-1, the criteria of calculation boundaries of those two vary in some degree, and that can cause great difference in the primary energy balance. In the calculation of the energy balance the criteria of syn.ikia considers all common energy uses in a building, including heating, cooling, ventilation, dehumidification, domestic hot water and lighting, while the Spanish Technical Code excludes lighting consumption. The main difference however is caused due to the fact that in syn.ikia hypothesis the exported energy is being considered in the calculation of how much non-renewable energy is avoided from the grid, while Spanish Technical Code excludes it. For the evaluation of these differences, a simplified monthly primary energy calculation tool is developed during the evaluation framework of key performance indicators of the project. The analysis of the calculation framework hypothesis is presented, analyzing the effects of the assessment boundaries, different primary energy balance calculation hypothesis and building design alternatives.
\end{abstract}

\section{Introduction}

Primary Energy consumption is used as one of the main indicators for the assessment of the energy balance in the Energy Performance of Building Directive (EPBD) and adopted in most of the countries in Europe. ISO 52000-1 is the European standard that defines the overarching framework and procedures for the EPB assessment and distinguishes between non-EPB uses (appliances and lighting in some cases for residential) and two different forms of the energy balance. The different forms vary in the consideration of the resources avoided by the external grid due to the export of the energy carrier, and each EU country can choose what considerations to apply in the energy balance [1].

The definition of a Plus Energy Building (PEB) follows up on the concept of a building that produces more energy from renewable sources than it consumes to achieve appropriate indoor environmental quality and cover the building energy needs (excluding plug loads) [1]. Furthermore, the PEBs should contribute to the rollout of renewable heating and energy recovery systems (solar thermal, aero/geo-thermal, biomass), as well as to the production of renewable electricity from different sources (solar panels, wind, cogeneration, etc.).

The renewable energy consumed in a PEB must mainly be produced on-site. On-site refers to energy sources that are in, on, under, or adjacent to the building. As a rule of thumb, the generation of energy must take place within the perimeter of the development, property, in a closed grid, or within a specific distance from the perimeter of the building. However, electricity generated by dedicated renewable energy systems in the region, as well as biomass which is supplied, is not necessarily regarded as an import.

Primary energy balance is one of the main key performance indicators to evaluate the energy and environmental performance of a building [2] and therefore an important criteria to consider in the integrated energy design process of a PEB. This work focuses on analyzing: the assessment boundaries and therefore considering which consumptions are included in the EPB uses; the exported energy considerations in the primary energy balance; the building design alternatives in order to achieve the PEB, depending on the energy balance used for the evaluation.

\footnotetext{
*Corresponding author: meril.tamm@taltech.ee
} 


\section{Demonstration site}

\section{1 syn.ikia project}

The EU project syn.ikia, from Horizon 2020 research and innovation programme, aims at achieving sustainable plus energy neighbourhoods with more than $100 \%$ energy savings, $90 \%$ renewable energy generation triggered, $100 \%$ GHG emission reduction, and $10 \%$ life cycle costs reduction, compared to nZEB levels. This will be achieved while ensuring high quality indoor environment and well-being. Syn.ikia's concept relies on the interplay between novel technologies at the neighbourhood scale, energy efficiency and flexibility of the buildings, good architectural and spatial qualities, sustainable behaviour,and citizen engagement.

The analysis of this work are carried out of the Mediterranean demonstration site of the project syn.ikia, that is located in Santa Coloma de Gremanet, Catalonia. A new PEB will be built in the Fondo neighbourhood, that is involved in an urban regeneration process. This aims to create open spaces in a neighbourhood, to refurbish the buildings of the affected area and to get better habitability at the surrounding buildings. The building is planned to be constructed in 2022 and therefore all the data presented are simulation results following the hypothesis explained below.

\subsection{Building description}

The building has 38 dwellings, 2 commercial premises and 30 parking lot, from which the 38 dwellings are in the scope of syn.ikia.

The building has 2 blocks ( Figure 1 and Figure 2), the bigger one which has its external side oriented to north west (lower block on Figure 2) and smaller to south east (higher block on Figure 2). In between of the 2 blocks is an open courtyard and the entrance to the households is also provided from the courtyard side. A typical dwelling consists of 2 bedrooms, 1 bathroom and one open kitchen/living room.

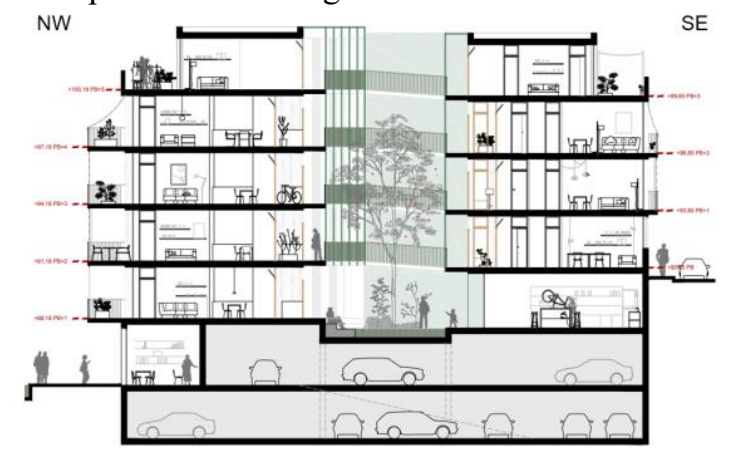

Figure 1. Architectural drawing of the Mediterranean demo site building.

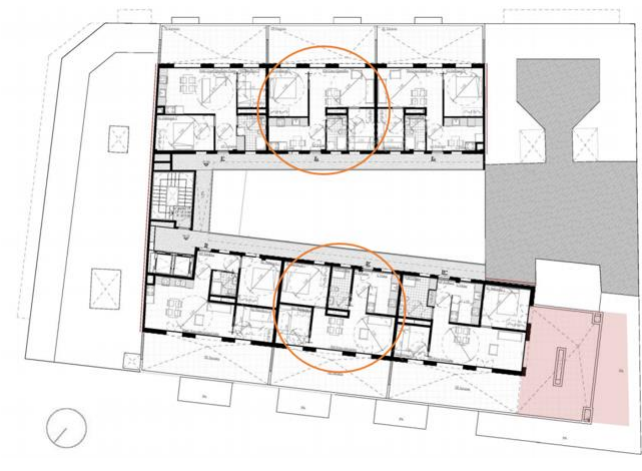

Figure 2. Architectural drawing of the Mediterranean demo site building's attic floor. Detailed households are circled with orange.

The envelope properties of this building are presented in Table 1.

Table 1. Envelope properties of the building.

\begin{tabular}{|c|c|c|}
\hline Parameter & Value & Unit \\
\hline External wall, U-value & 0.273 & $\mathrm{~W} / \mathrm{m}^{2} \mathrm{~K}$ \\
\hline Roof, U-value & 0.331 & $\mathrm{~W} / \mathrm{m}^{2} \mathrm{~K}$ \\
\hline Floor, U-value & 0.463 & $\mathrm{~W} / \mathrm{m}^{2} \mathrm{~K}$ \\
\hline Window, U-value & 1.4 & $\mathrm{~W} / \mathrm{m}^{2} \mathrm{~K}$ \\
\hline Window, SHGC & 0.7 & - \\
\hline Infiltration rate & 0.4 & $\mathrm{~h}^{-1}$ \\
\hline
\end{tabular}

The building has operative temperature driven ventilation control (that imitates the occupant behaviour when opening/closing the windows) and both radiation and operative temperature driven solar shading control, which are presented in Table 2. The heating, cooling and Domestic Hot Water (DHW) system is a 4-pipes system that consists of three air-to-water heat pumps with low temperature radiators as emitters.

Table 2. Configuration of technical systems.

\begin{tabular}{|l|l|l|}
\hline Parameter & \multicolumn{1}{|c|}{ Value } & \\
\hline $\begin{array}{l}\text { Ventilation } \\
\text { rate }\end{array}$ & $4 \mathrm{~h}^{-1}$ & $\begin{array}{l}\text { ON: Top }=24 \ldots 28^{\circ} \mathrm{C} \text { or } \\
\text { Top }>28^{\circ} \mathrm{C} \& \text { Top }>\text { Tout }\end{array}$ \\
\hline $\begin{array}{l}\text { Solar } \\
\text { shading }\end{array}$ & $\begin{array}{l}\text { Shading factor: } \\
0.7\end{array}$ & $\begin{array}{l}\text { ON: Top }>24.5^{\circ} \mathrm{C} \& \\
\text { Rs }>140 \mathrm{~W} / \mathrm{m} 2 \\
\text { OFF }: \text { Top }<24.5^{\circ} \mathrm{C} \text { or } \\
\text { Rs }<120 \mathrm{~W} / \mathrm{m} 2\end{array}$ \\
\hline $\begin{array}{l}\text { PV } \\
\text { production }\end{array}$ & $\begin{array}{l}\text { Production: } \\
48,818 \mathrm{kWh} / \mathrm{yr}\end{array}$ & $\begin{array}{l}\text { Total power: } 39.1 \mathrm{kWp} \\
\text { slope: } 30^{\circ} ; \text { SE oriented panels }\end{array}$ \\
\hline $\begin{array}{l}\text { Heating, } \\
\text { cooling } \\
\text { and DHW }\end{array}$ & COP: 4.98 & $\begin{array}{l}\text { Capacity: } 50.4 \mathrm{~kW} \\
\text { Power: heating } 11.94 \mathrm{~kW}, \\
\text { cooling } 10.91 \mathrm{~kW} .\end{array}$ \\
\hline
\end{tabular}

The building has local energy production from photovoltaic panels, which are placed both on northwest and south-east block roof. All the panels have a $30^{\circ}$ slope and oriented to south east (Figure 3).

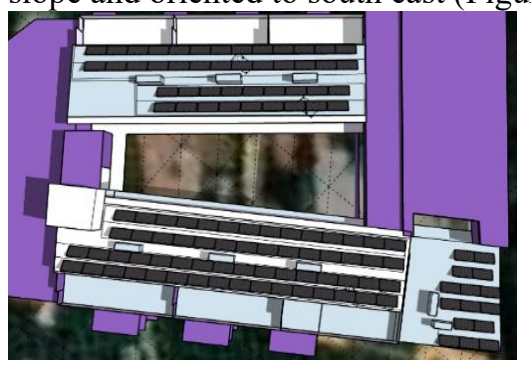

Figure 3. Base case PV design. All panels oriented to south east. 


\section{Methodology}

\subsection{Simulation}

\subsubsection{Simulation tools}

The simulations of the building are carried out with a transient system simulation tool TRNSYS 18 [3], using SketchUp [4] as a 3D interface. For the evaluation of local energy production from solar panels, PV design and yield forecast software Archelios [5] is used together with 3D interface SketchUp.

\subsubsection{Simulation model}

The 3D model of this building has 32 zones from which there is typically 1 zone per household, but for detailed comfort analysis there are 4 reference households that each have 1 zone per room (4 zones in a household). 2 of the reference households are located on the typical and 2 on the attic floor. In both floors, there is one reference household located in the north west block and one in the south east block (Figure 2).

The real building has 6 floors above the ground. First floor holds commercial areas and upper 5 floors are residential households. The second floor of the building holds a common bicycle parking area (Figure 1). The building has parking lots on 2 floors (1st and -1st floor). In order to reduce the computation time of the simulation, 3 floors have been simplified in the $3 \mathrm{D}$ model and are not included as thermal zones; the commercial areas on the first floor have been included in the model, but are not considered in the analysis of the building's thermal behavior; the parking lot which is on the 1st floor is added to the model as a nonacclimatized zone, yet has not been included in the thermal analysis on the building; the subfloor parking has not been included in the model (Figure 4).

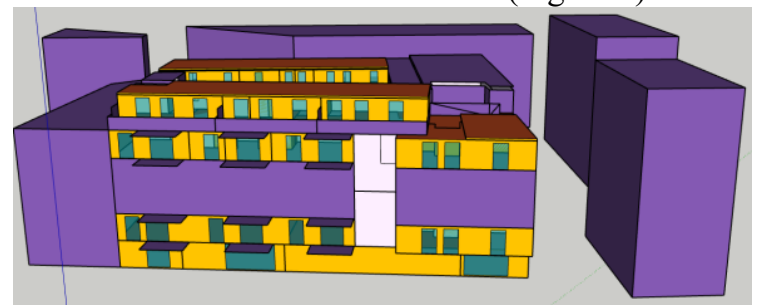

Figure 4. The north west façade of the 3D model of Mediterranean demo site.

\subsection{Key Performance Indicators}

\subsubsection{Total primary energy}

Primary energy takes into consideration all types of energy consumed and produced by the system, and the exchange with the energy networks. It is used as one of the main indicators for the assessment of the energy balance calculation. ISO 52000-1 defines the overarching framework and procedures for the EPB assessment and there are different forms of consideration of the resources avoided by the external grid due to the export of the energy carrier. Each EU country can choose what considerations to apply in the energy balance.

In general, the primary energy calculation of ISO 52000-1 consists of two calculation steps, called "Step A" (Figure 5) and "Step B" (Figure 6). Depending on national standards, the primary energy calculation can whether consist both "Steps" (if k_exp=1) or finish at "Step A" (if k_exp=0). In "Step A" the weighted produced and delivered energy is reduced by the "cost" of generating the exported energy. In order to calculate primary energy, final energy has to be multiplied with corresponding weighting factor of the energy carrier.

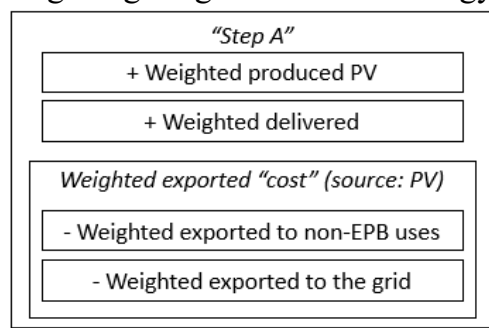

Figure 5. "Step A" of primary energy calculation of ISO 52000-1 for an all-electric building with on-site PV production.

The "Step B" (Figure 6) is the part of the primary energy balance calculation of ISO 52000 that takes into account the energy exported from the calculation boundary and accounts it as a "benefit".

The "benefit", conceptually speaking, reduces the primary energy use of the building by the amount of energy (both renewable and non-renewable) that due to the export of energy is avoided to be generated by the grid. The "net benefit" (that in the end is subtracted from the primary energy use) is a result of the total "benefit" minus the "cost" (the energy that is used to generate the exported energy). Even though all the exported energy is generated by renewable energy (in our building the source is PV), then for the "benefit" calculation, in order to evaluate how much grid-generated energy is avoided, the calculation is carried out with the weighting factors of grid electricity (considering the source to be grid instead [1].

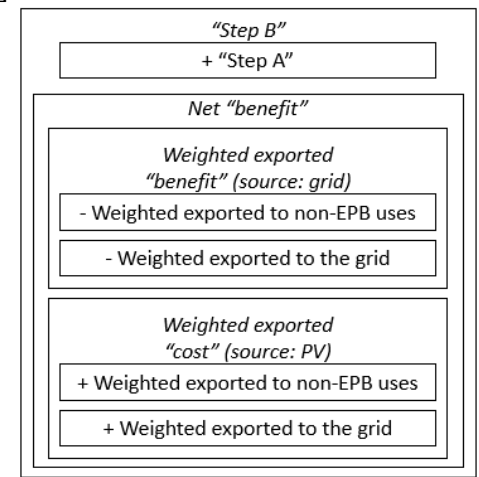

Figure 6. "Step B" of primary energy calculation of ISO 52000-1.

The total primary energy consists of both, renewable and non-renewable primary energy and is expressed in equation (1).

$$
E_{P . t o t}=E_{P, \text { ren }}+E_{P, \text { nren }}
$$


where $E_{P, \text { tot }}$ is total primary energy in $\mathrm{kWh} / \mathrm{m}^{2} \cdot \mathrm{yr} ; E_{P, \text { ren }}$ is renewable primary energy in $\mathrm{kWh} / \mathrm{m}^{2} \cdot \mathrm{yr}$; and $E_{P \text {,nren }}$ is non-renewable primary energy in $\mathrm{kWh} / \mathrm{m}^{2} \cdot \mathrm{yr}$. The way to incorporate weighting factors in the primary energy calculation, is expressed in equation (2).

Either using calculations or measured values, it is recommended that the interval period used to calculate the balance per energy carrier has one-hour resolution, as maximum. The simulation timestep of this study is 15 minutes.

\subsubsection{Non-renewable primary energy}

Non-renewable primary energy is the part of total primary energy that has non-renewable origin. It is calculated using equation (2) which sums up all delivered and exported energy for all energy carries into a single indicator with the corresponding non-renewable primary energy weighting factors. Therefore, this indicator considers as well differences in the energetic effort within the supply chain of different energy carriers, e.g. domestic gas versus electricity [2].

$$
\begin{gathered}
E_{P, \text { nren }}=\sum_{i} E_{p, \text { nren,del, } i}-\sum_{i} E_{p, \text { nren,exp }, i}=\sum_{i} \int P_{\text {del, } i}(t) . \\
w_{\text {nren,del, } i}(t) \cdot d t-\sum_{i} \int P_{\text {exp }, i}(t) \cdot w_{\text {nren,exp }, i}(t) \cdot d t
\end{gathered}
$$

where $E_{P, \text { nren }}$ is non-renewable primary energy in $\mathrm{kWh} / \mathrm{m}^{2} \cdot \mathrm{yr} ; E_{P, \text { nren,del, } i}$ and $E_{P, \text { nren,exp, } i}$ are delivered and exported non-renewable primary energy per energy carrier $i$ in $\mathrm{kWh} / \mathrm{m}^{2} \cdot \mathrm{yr} ; P_{d e l, i}$ and $P_{\text {exp }, i}$ are delivered and exported power on site or nearby for energy carrier $i$ in $\mathrm{kW} / \mathrm{m}^{2} ; \quad w_{\text {nren,del, } i}$ and $w_{\text {nren,exp,I }}$ are non-renewable primary energy conversion factor for the delivered and exported energy carrier $i$.

\subsubsection{Supply cover factor}

The supply cover factor is the relation between the energy produced on-site and directly used by the EPB uses and the total on-site produced energy as expressed in equation (3). In ISO 52000-1, this factor is named production matching fraction.

$$
\gamma_{\text {supply }}=\frac{E_{\text {prod, used }}}{E_{\text {prod,tot }}}=\frac{\int \min \left[P_{\text {prod }}(t), P_{\text {used }}(t)\right] d t}{\int P_{\text {prod }}(t) d t}
$$

where $\gamma_{\text {supply }}$ is the supply cover factor; $E_{\text {prod,used }}$ and $E_{\text {prod,tot }}$ are the self-consumed and total electricity produced on-site in $\mathrm{kWh} ; P_{\text {prod }}$ and $P_{\text {used }}$ are on-site produced and used (consumed) power in $\mathrm{kW}$.

The supply cover factor is influenced both by the design of the PV system and the EPB uses' boundary. The calculations have to be done by every timestep.

\subsubsection{Net energy/ net power}

Net energy can be used to characterize the interaction of a system with the energy grids over a certain period: a day, a week, a month or a year. For each energy carrier, the net energy indicator can be represented by a "curve of duration", where the values of the power obtained during a period are ranked from the lowest value to the highest one. The convection shown in this paper is that negative values represent power/energy exported out from the assessment boundary and positive values represent that the power/energy is delivered from the grid to the assessment boundary.

$E_{n e t, i}=\int P_{n e t, i}(t) \cdot d t=\int\left[P_{d e l, i}(t)-P_{\text {exp }, i}(t)\right] d t$

where $E_{\text {net }, i}$ is the net energy in $\mathrm{kWh} ; P_{\text {net }, i}$ is the net power in $\mathrm{kW} ; P_{d e l, i}$ and $P_{\text {exp }, i}$ the delivered and exported net power in $\mathrm{kW}$.

\subsection{Primary energy balance calculation hypothesis}

EPB has a high dependence on the stablished energy balance boundaries. This work introduces three levels of assessment boundaries, that are introduced in Table 3 . The primary energy balance calculation defines EPB uses inside the assessment boundary and non-EPB uses outside. The energy exported to the non-EPB uses is considered the same way as the grid-exported energy. The assessment boundaries define therefore the input to primary energy calculation, defining whether a consumption is considered as EPB or non-EPB use.

Table 3. Assessment boundary levels.

\begin{tabular}{|c|c|c|}
\hline $\begin{array}{c}\text { Assessment } \\
\text { boundary name }\end{array}$ & EPB uses & $\begin{array}{c}\text { Non-EPB } \\
\text { uses }\end{array}$ \\
\hline$H V A C+D H W$ & Heating, Cooling, DHW & $\begin{array}{c}\text { Lighting, } \\
\text { Appliances }\end{array}$ \\
\hline $\begin{array}{c}H V A C+D H W \\
+L I G\end{array}$ & $\begin{array}{c}\text { Heating, Cooling, DHW, } \\
\text { Lighting }\end{array}$ & Appliances \\
\hline$A L L U S E S$ & $\begin{array}{c}\text { Heating, Cooling, DHW, } \\
\text { Lighting, Appliances }\end{array}$ & - \\
\hline
\end{tabular}

Secondly, three primary energy balance calculation hypothesis are introduced, as Table 4 shows. Those three primary energy balance calculation hypothesis vary in assessment boundary, supply cover factor and in how the export of energy is considered through the k_exp. Spanish Technical Code, "CTE" case, considers " $H V A C+D H W$ " as EPB uses, while "syn.ikia" includes also lighting consumption and "syn.ikia_ALL" considers all the uses in the building as EPB uses. In case of "CTE", the supply cover factor is always 1 , while "syn.ikia" hypothesis use the actual supply cover factor. The greatest difference in the balance though is caused due to the $\mathrm{k}$ exp. CTE dictates also that the exported energy is not accounted as "benefit" in Primary energy balance, and therefore $\mathrm{k} \_\exp =0$.

Table 4. Primary energy balance calculation hypothesis.

Table 4. Primary energy balance calculation hypothesis.
\begin{tabular}{|c|c|c|c|}
\hline $\begin{array}{c}\text { Primary } \\
\text { Energy balance } \\
\text { hypothesis }\end{array}$ & $\begin{array}{c}\text { Assessment } \\
\text { boundary }\end{array}$ & $\begin{array}{c}\text { Supply cover } \\
\text { factor }\end{array}$ & k_exp \\
\hline$C T E$ & $H V A C+D H W$ & 1 & 0 \\
\hline syn.ikia & $\begin{array}{c}H V A C+D H W \\
+L I G\end{array}$ & Actual & 1 \\
\hline syn.ikia_ALL & $A L L U S E S$ & Actual & 1 \\
\hline
\end{tabular}

The primary energy weighting factors used for all of the three balance hypothesis are the ones of the Spanish national regulation and are presented in Table 5, where fren stands for renewable part weighting factor and fnren for non-renewable [6]. 
Table 5. Primary energy weighting factors of Spain.

\begin{tabular}{|c|c|c|}
\hline Primary energy source & fren & fnren \\
\hline Grid electricity & 0.414 & 1.954 \\
\hline Produced PV electricity & 1 & 0 \\
\hline Environmental heat & 1 & 0 \\
\hline
\end{tabular}

\subsection{Design alternatives}

There are six design alternatives introduced in this work that are presented in Table 6. The base case (BC) is considered as reference and has the heating, cooling and PV production values that are in Table 2. The second design alternative has twice lower PV production than $\mathrm{BC}$ (PV_L), while the third case has twice higher one (PV_H), which is difficult to achieve in reality, but will give a clear view of the impact of a higher on-site PV production. The fourth case has lower heating and cooling demand (PF_L), while case five has higher ones (PF_H) in comparison to the $\mathrm{BC}$. The last design alternative aims to reach the nZEB concept nZEB), so that the building would have a nearly zero energy balance, and for this purpose, the PV production is reduced $20 \%$ of the $\mathrm{BC}$ one.

Table 6. Design alternatives.

\begin{tabular}{|c|c|c|c|}
\hline & $\begin{array}{c}\text { Heating } \\
\text { demand }\end{array}$ & $\begin{array}{c}\text { Cooling } \\
\text { demand }\end{array}$ & $\begin{array}{c}\text { PV } \\
\text { production }\end{array}$ \\
\hline BC & Ref & Ref & Ref \\
\hline PV_L & Ref & Ref & $0.5 \times$ Ref \\
\hline PV_H & Ref & Ref & $2.0 \times$ Ref \\
\hline PF_L & $2.0 \times$ Ref & $2.0 \times$ Ref & Ref \\
\hline PF_H & $0.5 \times$ Ref & $0.5 \times$ Ref & Ref \\
\hline nZEB & Ref & Ref & $0.8 \times$ Ref \\
\hline
\end{tabular}

\section{Results}

\subsection{Analysis of assessment boundary}

First analysis is carried out on the supply cover factor, while varying the EPB uses' boundary. The total consumptions of the building, together with the PV production are presented on Figure 7.

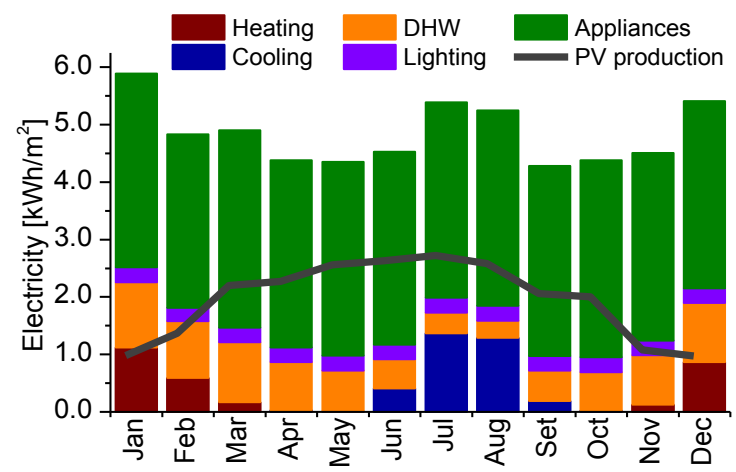

Figure 7. Total consumption of the building by energy uses and $\mathrm{PV}$ production of the base case.

The " $H V A C+D H W$ " assessment boundary includes heating, cooling and DHW, while " $H V A C+D H W+L I G$ " includes also lighting. The " $A L L$ USES" includes all the uses present in the building. The
PV production remained constant during the following analysis.

Higher values of supply cover factor can be reached in two ways: whether to increase the EPB uses or to lower the production. From the Figure 8 it can be clearly observed that the months with lower energy consumption result in lower supply cover factor. On the same time, while looking at Figure 7, when for example looking at "ALL USES" boundary, the total consumption of April and May are very similar, yet the supply cover factor of May is much lower, due to higher PV production.

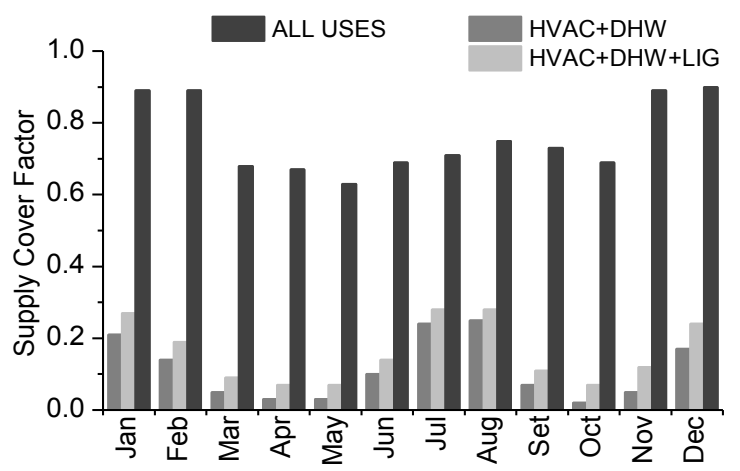

Figure 8. Comparison of Supply Cover factor of the base case for the different energy uses.

The way to have an overview of the annual performance of a building in terms of exported and delivered energy, is to analyse the net power duration curve (Figure 9). In case of "ALL USES" assessment boundary (which is the real case), where all the building uses are considered as EPB uses, energy is exported from the assessment boundary only $20 \%$ of the year, while in case of "HVAC+DHW+LIG", it is $41 \%$, and "HVAC+DHW" is $45 \%$. In all cases the actual performance of the building is the same, the only difference is evaluation boundary. As for "HVAC+DHW" the EPB uses are less than $50 \%$ of the "ALL USES", it creates a situation where on $46 \%$ of the year the building produces the amount of energy it consumes as only heating, cooling and DHW needs are accounted for. The minimum and maximum value of Figure 9 is the peak exported and peak delivered power, which is "ALL USES" case result in $27 \mathrm{~kW}$ and $205 \mathrm{~kW}$; and in "HVAC+DHW" and "HVAC+DHW+LIG" in 35 $\mathrm{kW}$ and $201 \mathrm{~kW}$ respectively. Therefore, the smaller the EPB uses, the more energy is exported, and the smaller the need for delivered energy.

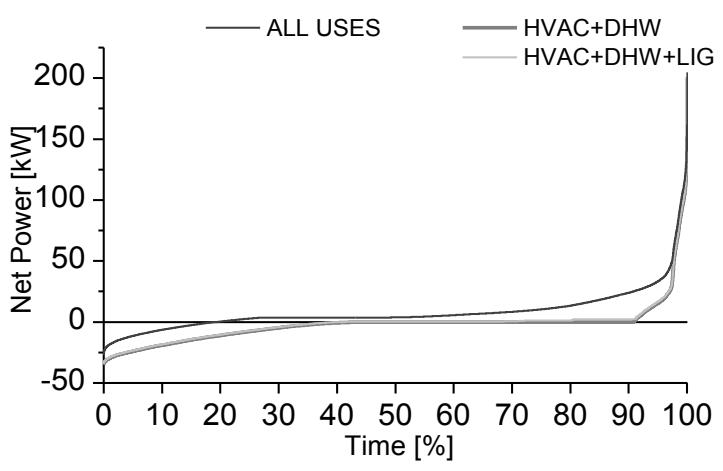


Figure 9. Net energy duration curve of the different assessment boundaries. Positive values represent the delivered energy, negative exported.

\subsection{Analysis of the Primary Energy balance hypothesis}

The first and second criteria that the Primary Energy balance calculation hypothesis set is the chosen assessment boundary together with the supply cover factor, which therefore determines the amount of (final) energy that is considered as self-consumed from the local PV production. The Figure 10 represents the EPB uses that are directly covered by the local production and is a result of Figure 7 (consumption the building) and Figure 8 (supply cover factors), dependent on the EPB uses considered in the assessment boundary and its correspondent supply cover factor, 1 for "CTE" balance and actual values for "syn.ikia" and "syn.ikia_ALL". On Figure 10 both "CTE" and "syn.ikia" case follow the tendency to have higher EPB used unweighted final energy consumption on winter (due to heating) and summer (cooling), while "syn.ikia_ALL", which considers all the uses in the building, has lower EPB used unweighted final energy consumption during the winter and increased consumption in the summer, as the appliances' consumption is also accounted for (Figure 7). For "syn.ikia_ALL", there is also a clear difference during November-February, where the EPB used unweighted final energy is only $11 \%$ lower than the PV production and this is caused due to the high supply cover factors (over 0.89 ) during those winter months (Figure 8). The "CTE" case "anomaly" that during November-February all the available PV production is used $100 \%$ to cover the EPB uses (even though Figure 8 indicates the maximum value for "CTE" case only 0.25 ), is caused due to the CTE defined regulation that supply cover factor has to be 1 instead of the actual one. This regulation leads to the over-evaluated, optimistic self-consumption. This in the end causes greater than $80 \%$ off-set between "CTE" and "syn.ikia" case, even though they differ only in lightings consumption $(16 \%$ of the total EPB uses of "syn.ikia") by the assessment boundary.

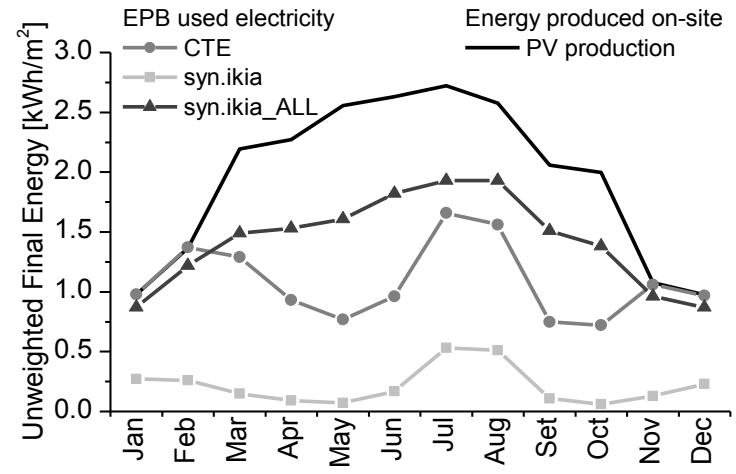

Figure 10. EPB used unweighted final energy consumption of the different Primary Energy balance hypothesis and the PV production.

The third and most important criterion that the Primary Energy balance calculation hypothesis sets is how in the primary energy balance the exported energy in accounted for.

The Figure 11 represents the "net benefit", in terms of total weighted exported primary energy and is the result of unweighted exported energy and the corresponding total grid exporting weighting factor. As in the "CTE" case the exported energy is not accounted as "benefit" in the Primary Energy calculation ("Step B"), there is no weighted export of energy in Figure 11 all through the year even though Figure 10 indicates that during March-October there is export of energy. The main difference between "syn.ikia" and "syn.ikia_ALL" is the EPB assessment boundary, making that "syn.ikia" has a higher weighted exported Total Primary Energy than "syn.ikia_ALL, as the appliances are not included in the EPB assessement.

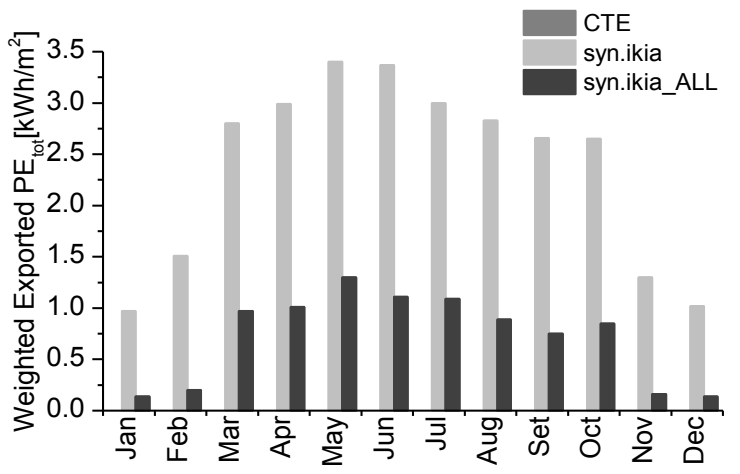

Figure 11. Weighted exported total primary energy of different primary energy balance hypothesis.

The monthly primary energy results are presented in Table 7. The non-renewable primary energy consumption of "CTE" hypothesis during MarchNovember is 0 , as the exported energy is not considered in the Primary Energy balance. In case of "syn.ikia", due to the higher PV production during the summer months, the building is exporting energy during MarchOctober, and reaches the balance in November, as the non-renewable primary energy consumption is 0 . In case of "syn.ikia_ALL" the building is not exporting the energy and the lowest non-renewable consumption can be observed during the summer months that the overall EPB consumption is the lowest (April-June and September).

Table 7. Monthly non-renewable and total primary energy results in $\mathrm{kWh} / \mathrm{m}^{2}$.

\begin{tabular}{|c|c|c|c|c|c|c|c|c|c|c|c|c|c|c|}
\hline & $\begin{array}{l}\text { PE balance } \\
\text { hypothesis }\end{array}$ & 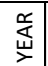 & $\underset{\leq}{z}$ & 蚛 & $\frac{\alpha}{\Sigma}$ & $\frac{o}{\frac{\alpha}{\alpha}}$ & $\frac{\grave{c}}{2}$ & \. & 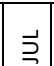 & $\stackrel{\text { Oे }}{\gtrless}$ & 岕 & ť & oे & 岀 \\
\hline $\bar{\Phi}$ & CTE & 5 & 3 & 1 & 0 & 0 & 0 & 0 & 0 & 0 & 0 & 0 & 0 & 2 \\
\hline & syn.ikia & -9 & 3 & 1 & -1 & -2 & -3 & -3 & -2 & -1 & -2 & -2 & 0 & 3 \\
\hline 岀 & syn.ikia_ALL & 69 & 10 & 7 & 5 & 4 & 4 & 4 & 5 & 5 & 4 & 5 & 7 & 9 \\
\hline to & CTE & 44 & 9 & 5 & 3 & 2 & 2 & 2 & 3 & 2 & 2 & 2 & 3 & 8 \\
\hline$=1$ & syn.ikia & 37 & 10 & 6 & 3 & 1 & 0 & 1 & 2 & 2 & 1 & 1 & 3 & 8 \\
\hline & syn.ikia_ALL & 131 & 18 & 13 & 11 & 9 & 8 & 8 & 10 & 10 & 9 & 9 & 11 & 16 \\
\hline
\end{tabular}

The annual results of total and non-renewable primary energy of the three Primary Energy balance hypothesis are presented in Figure 12. Even though the performance of the building is the same in all three cases, the Primary Energy varies in great degree, showing export of energy only in "syn.ikia" balance (PEren is negative). "CTE" balance cannot provide a negative value per definition, as the exported energy is 
not counted as a benefit, and "syn.ikia_ $A L L$ " need much more renewable energy production on-site to be a PEB. However, comparing the results of "CTE" and "syn.ikia" balance, it can be concluded that in both cases a high energy performance has been achieved with the current design, even though the PEB can be visualised with a negative value $(<=0)$ only when using "syn.ikia" hypothesis. CTE defines nZEB consumption limits of non-renewable and total primary energy which are $32 \mathrm{kWh} / \mathrm{m}^{2} \mathrm{yr}$ and $64 \mathrm{kWh} / \mathrm{m}^{2} \mathrm{yr}$ respectively [6], which the base case building design respects.

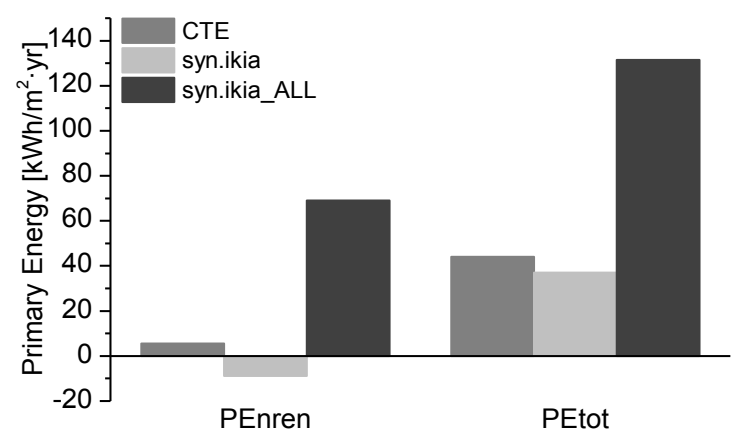

Figure 12. Annual comparison of primary energy of the three primary energy balance hypothesis.

\subsection{Evaluation of building design alternatives}

To evaluate how different design options affects the primary energy balance, different alternatives has been calculated, as introduced in Table 6 . The primary energy balance obtained in each case is presented in Figure 12 and Table 8 and discussed below:

- If to decrease the PV production by $50 \%$, then the "CTE" non-renewable Primary Energy consumption increase by $51 \%$, however its total Primary Energy consumption increase only an $8 \%$. In terms of total Primary Energy consumption, the increase has a similar order of magnitude, around $30 \%$.

- If to increase the PV production by $50 \%$, then the " $C T E$ " non-renewable Primary Energy consumption decrease, achiving values close to 0 . However, its total Primary Energy consumption decrease only by $7 \%$. By the hypothesis of "syn.ikia", the non-renewable and total Primary Energy consumption decrease around 85\%.

- If to increase the heating and cooling consumption by $50 \%$, then the "CTE" non-renewable Primary Energy consumption increase by $54 \%$ and the total by $31 \%$. Similar to PV_L, the "syn.ikia" balance does not provide exported energy in annual balance, and both, the non-renewable and total primary energy have increased by $38 \%$.

- If to decrease the heating and cooling consumption by $50 \%$, then the "CTE" non-renewable Primary Energy consumption decrease by $49 \%$ and the total by $22 \%$. By the hypothesis of "syn.ikia", the nonrenewable Primary Energy consumption decreases by $41 \%$, and the total by $32 \%$.
- If to decrease the PV production by $20 \%$ aiming to achieve zero balance, the "CTE" non-renewable Primary Energy consumption increases by $24 \%$ and the total by $3 \%$. For the syn.ikia balance, the non-renewable primary energy is almost 0 , which correspond with the objective of ZEB, and its total Primary Energy consumption increases by $15 \%$.

From this comparison, different aspects can be highlighted: To improve the CTE balance in terms of non-renewable and total Primary Energy, it is needed to reduce the demand, otherwise the total Primary Energy consumption is not improved substantially.

The improvement of the syn.ikia balance can be done reducing the buildings demand and increasing the $\mathrm{PV}$ production, as the exported energy is considered as benefit in the balance.

As the energy consumed is equal or greater than the on-site renewable energy production, the balance of CTE and syn.ikia provides closer results.

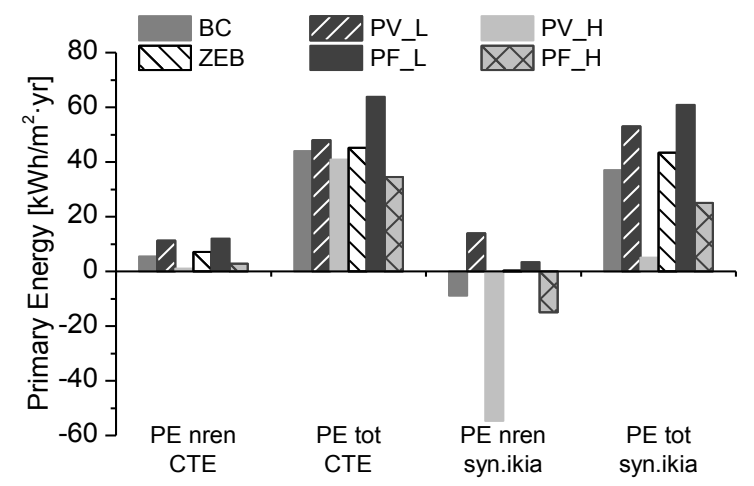

Figure 13. Non-renewable and total primary energy consumption of the different design alternatives over "CTE" and "syn.ikia" primary energy balance hypothesis.

Table 8. Characteristics and results of the building design alternatives

\begin{tabular}{|c|c|c|c|c|c|c|}
\hline & U & $\vec{a}^{\prime}$ & $\begin{array}{l}\pi_{1} \\
z^{\prime}\end{array}$ & $\frac{1}{a}$ & $\frac{x^{\prime}}{a}$ & 空 \\
\hline $\begin{array}{l}\text { HVAC+DHW } \\
\text { consumption }\end{array}$ & 16 & 16 & 16 & 22 & 13 & 16 \\
\hline Lighting & \multirow{2}{*}{3} & & \multirow{2}{*}{3} & \multirow{2}{*}{3} & \multirow{2}{*}{3} & \multirow{2}{*}{3} \\
\hline Consumption & & & & & & \\
\hline PV production & 23 & 12 & 47 & 23 & 23 & 19 \\
\hline $\begin{array}{l}\text { Supply cover } \\
\text { factor }\end{array}$ & 0.2 & 0.2 & 0.1 & 0.2 & 0.1 & 0.2 \\
\hline EP_nren_CTE & 6 & 11 & 1 & 12 & 3 & 7 \\
\hline EP_tot_CTE & 44 & 48 & 41 & 64 & 35 & 45 \\
\hline EP_nren_syn.ikia & -9 & 14 & -55 & 3 & -15 & 0 \\
\hline EP_tot_syn.ikia & 37 & 53 & 5 & 61 & 25 & 43 \\
\hline
\end{tabular}

\section{Conclusions}

In current work, three aspects that affect primary energy balance of PEB are analysed: the assessment boundary, the primary energy balance calculation hypothesis and building design alternatives. The 
purpose of all of those 3 aspects are to evaluate the impact of primary energy balance of the integrated energy design process of the PEB.

In general, the primary energy balance can be improved in two ways: whether to increase the PV production or to lower the EPB consumption. The EPB consumption can be decreased whether by more efficient systems and therefore by lower demand, by more energy efficient user behaviour and therefore lowered demand, or by artificially setting the EPB boundaries over restricted energy consumption. In case of "CTE", only heating, cooling and DHW consumption are considered as EPB uses, and therefore the EPB demand of the building is lower than in the case of "syn.ikia" (that includes also lighting in EPB boundary) and "syn.ikia_ALL" (that includes all the uses in the building, that in the end is the real case of the building). Even in the case where all the uses in the building are considered as EPB uses ("syn.ikia_ALL"), there is still export of energy, as the matching of PV production and consumption is lower than 1 .

In all of those previously mentioned primary energy balance hypothesis the real consumption and performance of the building is the same, yet the differences vary in great degree due to the artificially set calculation boundary, so indicative limits or requirements should be established with the same hypothesis.

In case the weighting factors of delivered energy and exported energy are equal, there is no effect in changing the supply cover factor in terms of primary energy consumption, as the weighted result stays the same (case "syn.ikia"). Therefore, if not to consider the economic aspects of integrated energy design and there are no limitations of budget nor space, "syn.ikia" primary energy balance hypothesis don't encourage to be energy efficient and reduce the EPB consumption and/or increase the self-consumption, as all the exported energy is accounted with the same weighting factors as selfconsumed energy. In reality though, the optimal integrated design is a result on both primary energy balance and cost-optimal solutions [7], requiring the use of a holistic set of indicators, as presented in the "Methodology Framework for Plus Energy Buildings and Neighbourhoods" of syn.ikia [2].

In case of "CTE", as there is no weighted exported energy, the way to improve the primary energy balance is to improve the performance of the building (lower the EPB consumption) and increase the PV production in order to lower the need for delivered energy. Even though the primary energy balance increasing options for "syn.ikia" are the same, the impact of increasing the PV production on the primary energy balance, is 12 times higher than in "CTE". Doubling the PV in case of "CTE" resulted in 7\% lower total primary energy consumption, while in case of "syn.ikia", the drop is $86 \%$.

Using the primary energy balance hypothesis of "CTE" and using the artificial supply cover factor 1 does not help the architects and engineers to be conscious about the actual exported nor the available energy to be used for non-EPB uses, when making the monthly primary energy balance. The way of calculating the primary energy balance, does not allow the balance to drop under 0 . The only way to achieve the 0 -balance would be the perfect and complete monthly coverage of all the EPB consumption in all the months.

The research conducted in this paper is part of the SYN.IKIA project (www.synikia.eu) project that has received funding from the European Union's Horizon 2020 research and innovation programme under grant agreement No 869918".

\section{References}

[1] International Standard ISO 52000-1:2017 (E). Overarching EPB assessment - General framework and procedures, 2017.

[2] J. Salom, M. Tamm, J. Pascual et al. "Technology Integration in Smart Managed Plus Energy Buildings and Neighbourhoods. syn.ikia.," 3009 2020. [Online]. Available: https://www.synikia.eu/wpcontent/uploads/2020/12/D3.1_Methodologyframework-for-Plus-Energy-Buildings-andNeighbourhoods.pdf. [Accessed 0202 2021].

[3] SEL, TRNSYS 18.02, Madison: Solar Energy Laboratory. University of Wisconsin, 2012.

[4] 2021 Trimble Inc., SketchUp Pro, 2021.

[5] 2020 Trace Software International, archelios TM PRO Gold, 2020.

[6] Documento Básico HE Ahorro de Energía (CTE), 2019.

[7] J. Ortiz, A. Fonseca, J. Salom, N. G. Soriano and P. Fonseca, "Cost-effective analysis for selecting energy efficiency measures for refurbishment of residential buildings in Catalonia," Energy \& Buildings, vol. 128, pp. 442-457, 2016.

[8] J. Stengel, "CONCERTO Premium: Indicator Guide," 2012. 